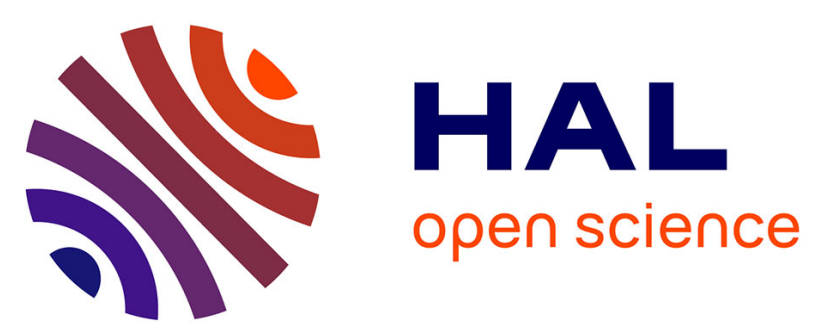

\title{
Role of MDM2 acid domain interactions in recognition and ubiquitination of the transcription factor IRF-2
}

Susanne Pettersson, Michael Kelleher, Emmanuelle Pion, Maura Wallace, Kathryn L Ball

\section{- To cite this version:}

Susanne Pettersson, Michael Kelleher, Emmanuelle Pion, Maura Wallace, Kathryn L Ball. Role of MDM2 acid domain interactions in recognition and ubiquitination of the transcription factor IRF-2. Biochemical Journal, 2009, 418 (3), pp.575-585. 10.1042/BJ20082087 . hal-00479113

\section{HAL Id: hal-00479113 https://hal.science/hal-00479113}

Submitted on 30 Apr 2010

HAL is a multi-disciplinary open access archive for the deposit and dissemination of scientific research documents, whether they are published or not. The documents may come from teaching and research institutions in France or abroad, or from public or private research centers.
L'archive ouverte pluridisciplinaire HAL, est destinée au dépôt et à la diffusion de documents scientifiques de niveau recherche, publiés ou non, émanant des établissements d'enseignement et de recherche français ou étrangers, des laboratoires publics ou privés. 


\section{Role of MDM2 acid domain interactions in recognition and ubiquitination of the transcription factor IRF-2}

Susanne Pettersson, Michael Kelleher, Emmanuelle Pion, Maura Waliace*, and Kathryn L. Ball

CRUK Interferon and Cell Signalling group, Cell Signalling Unit, IGMM University of Edinburgh, Edinburgh EH4 2XR, UK; " The Roslin Institute and $R(D) S V S$, University of Edinburgh, Easter Bush Veterinary Centre, Roslin, EH25 9RG

e.mail: kathryn.ball@ed.ac.uk Tel: 01317773560

Running title: MDM2 mediated ubiqitination of IRF-2

Key words: IRF-2, MDM2, ubiquitination signal, E3-ligase mechanism 


\begin{abstract}
MDM2-mediated ubiquitination of the p53 tumour suppressor requires interaction of the ligase at two distinct binding sites that form general multiprotein docking sites for the p53 protein. The first MDM2-binding site resides in the transactivation domain of p53 and is an allosteric effector site for MDM2-mediated p53 ubiquitination; the second site requires the acid domain of MDM2 to recognise a 'ubiquitination signal' within p53's DNA-binding core. In order to expand on fundamental requirements for a protein to function as a MDM2 substrate and the role of the acid domain in recognition, we have carried out a bioinformatics search for open reading frames which have homology to the MDM2 docking sites in p53. IRF-2, an interferon regulated transcription factor, has been identified as a MDM2 binding protein and substrate requiring interactions with both the hydrophobic pocket and the acid domain of MDM2. Mutation of either of two MDM2-binding sites on IRF-2 can attenuate substrate ubiquitination confirming the requirement of a dual-site substrate interaction mechanism. Ligands that bind to the hydrophobic pocket are not sufficient to inhibit MDM2-E3-ligase activity. Rather, acid domain binding ligands act as E3-ligase inhibitors lending additional support to the idea that the acid domain of MDM2 is key to understanding its mechanism of action. The ability of MDM2 and IRF-2 to form a complex in cells complements the biochemical assays and together establishes a novel substrate with which to develop insights into E3-ubiquitin ligase:substrate interactions in vitro and in cells.
\end{abstract}

\title{
Introduction
}

The tumour suppressor protein p53 is negatively regulated by components of the ubiquitin-dependent degradation machinery that direct p53 to the proteasome [1] and positively regulated by protein kinase cascades that assemble p53 into transcription complexes [2]. The MDM2 protein plays multiple regulatory roles in attenuating the function of p53 as a transcription factor including transrepression of p53-dependent gene expression [3]. However, it is the activity of MDM2 as an E3-ubiquitin ligase that has excited the most interest in recent years and which may explain the oncogenicity of MDM2 in cells which are null for p53 [4]. MDM2 catalysed ubiquitination of p53 leads to proteasomal degradation and thereby controls the steady state levels of the p53 protein in cycling cells. However, the biochemical mechanism describing how the core E1-E2-E3 system recognizes and ubiquitinates p53 is not fully defined.

The binding interface between MDM2 and p53 is complex and highly regulated. The transactivation domain of p53 (BOX-I) binds to a hydrophobic cleft in the N-terminus of MDM2 [5] leading to transrepression of p53 activity [3]. Occupation of the MDM2 hydrophobic pocket by the transactivation domain of p53 (BOX-I) generates conformational changes which favour further interactions between the acid domain of MDM2 and a surface in the core of p53 which encompasses the S9-10 linker and BOX-V motif [6-8]. It is this complex interface within the core DNA-binding domain of p53 that comprises the ubiquitination signal. Mutations in p53 that expose the MDM2-binding site in the DNA-binding domain lead to enhanced ubiquitination in tumour cell lines $[6,7]$ and a striking de-stabilization of the mutant p53 protein in murine transgenes [9]. 
The identification and molecular characterisation of novel substrates that would provide further insights into the structure, regulation and functions of MDM2 is an important goal for unravelling MDM2-mediated pathways in human diseases such as cancer. However, a paucity of studies which define substrate-ligase interfaces has to date limited structure-function analysis of MDM2. As one of the fundamental aspects of the MDM2-p53 ubiquitination reaction is that MDM2 interacts at two distinct interfaces, we have used search engines that can identify homologous linear interaction motifs that match the two-MDM2 docking sites in p53. Here we describe one such protein identified as IRF-2, an interferon regulated transcription factor [10]. This protein has two peptide motifs with highly significant homology to the two MDM2-docking sites in p53; indeed these two binding sites are required for MDM2-mediated ubiquitination of IRF-2 highlighting a fundamental ability of MDM2 to recognize a substrate via a dual-site docking mechanism. This defines a novel substrate for MDM2 that provides an independent tool with which to probe MDM2 structure-function relationships as an E3-ubiquitin ligase.

\section{Results}

\section{Complex formation between IRF-2 and MDM2}

Recent studies have highlighted the complex nature of the binding interface between MDM2 and its E3-ubiquitin ligase substrate p53 [6-8]. These studies suggest that the key 'signal' for p53 ubiquitination is binding of the MDM2 acid domain to a complex ubiquitination signal in the core DNA binding domain of p53 which encompasses its BOX-V/S9-10 linker region $[6,7]$. The relatively weak interaction between the MDM2 acid domain and p53-BOX-V is promoted by a higher affinity interaction between the hydrophobic pocket of MDM2 and the transactivation domain (BOX-I domain) of p53. In order to identify MDM2 substrates that may provide further support for the role of the acid domain in MDM2-mediated ubiquitination of target substrates we have used a bioinformatics approach. Using the MDM2 interacting motifs of p53 to screen for open reading frames with homology to the BOX-I and/or the BOX-V domains of p53 (Figure 1A) a number of putative MDM2 binding proteins were identified [6] amongst these was the transcription factor IRF-2. IRF-2 was chosen for further analysis as it had regions of homology with both the BOX-I and the BOX-V domains.

We first established whether IRF-2 and MDM2 could form a complex in cells. When IRF-2 and MDM2 were co-expressed in A375 cells and immunocomplexes captured using an anti-IRF-2 IgG, MDM2 protein was coprecipitated providing evidence that these two proteins are involved in interactions in a complex cellular background (Figure 1B, lane 5). Consistent with the ability of MDM2 to precipitate with IRF-2 (Figure 1B) the two proteins co-localised in the cell nucleus (Figure 1C) when GFP-IRF-2 was transfected into $\mathrm{H} 1299$ cells together with untagged MDM2.

In order to establish whether MDM2 and IRF-2 were able to bind directly or if additional factors were required the two human proteins were purified from an E.coli expression system and analysed using an ELISA format. A titration of purified MDM2 (Figure 1D; upper panel) or IRF-2 (Figure 1D; lower panel) was captured onto the solid phase and incubated with IRF-2 or MDM2 protein 
in the soluble phase, respectively, binding was then detected using an appropriate primary antibody. The data show that MDM2 and IRF-2 can interact directly in the absence of additional cellular factors.

\section{MDM2-dependent ubiquitination of IRF-2 in vitro and in cells}

Using a well-characterised assay [11], which measures the conjugation of Hisubiquitin to target proteins, we examined whether IRF-2 was a substrate for MDM2 E3-ligase activity in cells (Figure 2A). Immunoblots were used to analyse ubiquitin-conjugated proteins from crude cell lysates captured on $\mathrm{Ni}-$ agarose following the co-expression of IRF-2 and His-ubiquitin (Figure 2A). In this assay the presence of IRF-2 in the Ni-agarose pull-down was dependent on the presence of His-ubiquitin and no background IRF-2 binding was detected in its absence (Figure 2A). When MDM2 was co-expressed with IRF-2 and His-ubiquitin a discrete banding pattern of ubiquitinated IRF-2 protein forms was detected (Figure 2A; lane 5 vs 4). There was some background IRF-2 modification in the presence of His-ubiquitin alone which could be explained by endogenous MDM2 or other IRF-2-directed E3-ligases. When wild-type MDM2 was replaced by a RING finger domain mutant (MDM2/C464A) that looses the ability to ubiquitinate p53 [12], no increase in ubiquitinated IRF-2 was seen over background (Figure $2 A$, lane 9 vs 8 ).

We next wished to establish whether an in vitro assay could be used to measure the ubiquitination of IRF-2 by MDM2 as this would permit quantitative analysis to be carried out using mutant proteins. When purified full-length MDM2 was incubated with purified GST-IRF-2 (similar results were obtained with His-IRF-2; data not shown) in the presence of an E1-activating enzyme, E2-conjugating enzyme (UbcH5), ubiquitin and an ATP regeneration system, IRF-2 modification was dependent on the presence of both ubiquitin and MDM2. The reaction proceeded in a time- and [MDM2]-dependent manner (Figure 2B and 2C) demonstrating that MDM2 can act as an E3ubiquitin ligase for IRF-2 in this minimal system.

Previous studies have suggested that MDM2 can mediate multiple monoubiquitination of p53 although it is less clear whether MDM2 alone is sufficient to catalyse polyubiquitination of its substrates or whether polyubiquitination requires additional cellular factors. In order to determine if MDM2 mediated ubiquitination of IRF-2 represented mono- or polyubiquitination we used two monoclonal antibodies FK2, which recognises both mono- and polyubiquitin modified substrates, and FK1, which only binds to polyubiquitinated substrates. When these antibodies were used to probe IRF-2 ubiquitination assays FK2 picked up a discrete pattern of bands only when ubiquitinated forms of IRF-2 were present (Figure 3A lane 5 vs 6 ). In addition both FK1 and FK2 detected high molecular weight products, however these were seen in both the absence and presence of IRF-2 (Figure 3A; lanes 5,6,8,9). As the high molecular weight products were dependent on the presence of MDM2 they most likely represent MDM2 auto-polyubiquitination. In order to confirm that MDM2 was monoubiquitinating rather than polyubiquitinating IRF-2 we asked whether MDM2 could catalyse the attachment of K48 linked ubiquitin chains to IRF-2. When a mutant form of ubiquitin was used where K48 had been substituted with $R(K 48 R)$ it had no effect on the ability of MDM2 to 
ubiquitinate IRF-2, in fact K48R-ubiquitin appeared to be conjugated more efficiently to IRF-2 than wild-type ubiquitin (Figure 4B; lane 4 vs 2).

Experiments presented in this section suggest that MDM2 mediated ubiquitination of IRF-2 is primarily at the level of multi-monoubiquitination, suggesting that polyubiquitination would require additional cellular factors.

Structural requirements for MDM2-medated ubiquitination of IRF-2 Although the RING domain of MDM2 by itself is sufficient to act as an E3ubiquitin ligase (in cooperation with the $\mathrm{E} 2 \mathrm{UbcH}$; [13]) specific recognition of p53 as a MDM2 substrate requires a complex interaction between the two proteins. In order to determine if the ubiquitination of IRF-2 by MDM2 was specific we firstly asked whether, like modification of p53, the ubiquitination reaction required both the hydrophobic pocket and the acid domain of MDM2 to be present in addition to the RING. GST-MDM2 wild-type and mutant proteins where either the acid domain $(\Delta \mathrm{Ac})$ or the hydrophobic pocket $(\Delta \mathrm{N})$ had been deleted were purified and used in the in vitro ubiquitination reaction. Although the specific activity of GST-MDM2 wild-type is lower than untagged MDM2 (data not shown) it is still able to ubiquitinate IRF-2 (Figure 4A; lane 1). However, consistent with the mechanism of p53 ubiquitination by MDM2 [7], neither MDM2 $\triangle \mathrm{Ac}$ nor MDM2 $\Delta \mathrm{N}$ are able to act as E3-ligases for IRF-2 despite that fact that the RING domain was present. The data suggests that ubiquitination of IRF-2 by MDM2 occurs in a specific manner that relies not only on MDM2 E3-ligase activity but also on the efficient recognition of the substrate by determinants out with the RING.

IRF-2 was originally identified by us as a potential MDM2 substrate by virtue of its homology with the BOX-I and BOX-V/S9-10 MDM2 binding sites on p53 (Figure 1A). To determine if the p53 homologous regions of IRF-2 are required for MDM2 ubiquitination we made two IRF-2 mutant proteins (Figure 4B), IRF-2MI, where the BOX-I homology motif was mutated, and IRF-2MV, where the BOX-V homology motif was mutated. When the ability of MDM2 to ubiquitinate the mutant proteins was compared to wild-type IRF-2 there was a significant impairment (Figure $4 \mathrm{C}$ ). The data suggest that the interface between IRF-2 and MDM2, like that of p53 and MDM2, is complex and that at least two regions of IRF-2 must contact MDM2 to signal efficient ubiquitination.

\section{MDM2 acid domain interacting ligands inhibit MDM2-mediated ubiquitination of IRF-2}

The data presented above suggests a role for both the acid domain and the hydrophobic pocket of MDM2 in the specific recognition of IRF-2 as a substrate for its E3-ligase activity. To explore the relative significance of these two domains in the mechanism of MDM2-mediated ubiquitination of IRF-2 we used peptides or small molecular weight compounds that can bind to either the hydophobic pocket of MDM2 or to its acid domain (Figure 5A). Figure 5B shows that hydrophobic pocket interacting molecules (BOX-I peptide; PPLSQETFSDLWKLLP and Nutlin $[14,15])$ do not affect the ability of MDM2 to mediated ubiquitination of IRF-2, whereas $\mathrm{Rb} 1$

(DQIMMCSMYGICKVKNIDLK; [7]), an acid domain interacting peptide significantly reduces the ubiquitination of IRF-2. Further characterisation 
revealed that $\mathrm{Rb} 1$ could fully inhibit IRF-2 ubiquitination at a concentration of $25 \mu \mathrm{M}$, whereas the hydrophobic pocket binding ligand BOX-I had no inhibitory activity at this concentration. To further support the role of the acid domain in the mechanism of IRF-2 ubiquitin signal recognition we demonstrated that a second acid domain interacting peptide, this time based on the BOX-V domain of p53 (RNSFEVRVCACPGRD; [7]), could also inhibit IRF-2 ubiquitination all be it with an increased $\mathrm{I}_{0.5}$ compared to $\mathrm{Rb} 1$.

The data presented here and in the previous section (Figure 4) support a model where binding of the hydrophobic pocket of MDM2 to either full-length p53 or to the isolated BOX-I domain is needed to promote conformational changes in MDM2 which favour binding of the acid domain to the p53 core. Thus, BOX-I and Nutlin do not inhibit MDM2 mediated ubiquitination b mimic full-length p53 by generating conformational changes in the MDM2 that favour its E3-ligase function [7], where as acid domain binding peptides act as direct competitive inhibitors for binding to the ubiquitination signal in the core of p53.

\section{Ligand stimulated increases in MDM2 activity are mediated by the acid domain}

It has previously been suggested that MDM2 interacting ligands such as the RNA mimetic poly-G stabilise MDM2 in a conformation that favours binding to the BOX-V/S9-10 linker of p53 [6], leading to the hypothesis that such ligands might regulate MDM2 activity as an E3-ligase. As the acid domain of MDM2 is responsible for binding to the $B O X-V$ domain of $p 53$, we reasoned that a gain in acid domain binding should result in increased MDM2 E3-ligase activity. Using IRF-2 as a model substrate for MDM2 we first asked whether poly-G affected MDM2 and IRF-2 complex formation. When IRF-2 was immobilised on a micro-titre plate and incubated with a fixed amount of MDM2 that had been pre-incubated with a titration of poly-G low amounts of poly-G stimulated MDM2 binding to IRF-2 (Figure 6A). In contrast, when MDM2 is immobilised and IRF-2 is incubated with poly-G, no poly-G dependent increase is detected (Figure 6A; left panel) presumably because immobilized MDM2 can not undergo poly-G dependent conformational changes. This result also suggests that the poly-G is affecting MDM2 binding activity rather than IRF-2 activity. In order to determine if this gain in binding resulted in a gain in E3-ligase activity MDM2-dependent IRF-2 ubiquitination assays were set up in which ubiquitination of IRF-2 had not gone to completion. Poly-G was then titrated into the assay. At low amounts of poly- $G$ there was a significant stimulatory effect of the ligand on MDM2 activity, whereas higher amounts of poly-G inhibited ubiquitination.

Finally in order to establish whether increases in MDM3 E3-ligase activity observed in the presence of low amounts of poly-G (Figure 6B) were mediated through acid domain interactions with IRF-2 we determined whether the poly-G stimulated increase could still be inhibited by the acid domain interacting peptide Rb1. Figure $6 \mathrm{C}$ shows that at a concentration of poly- $\mathrm{G}$ which gives robust induction of MDM2-dependent IRF-2 ubiquitination Rb1 is an efficient inhibitor that completely ablates MDM2-mediated modification of IRF-2. 


\section{Discussion}

Progress in understanding the structure of MDM2 as it relates to its function and regulation is an important goal to inform the design of drugs aiming to target the different activities of MDM2 for therapeutic benefit [16]. One approach to further characterise key features of MDM2 structure and regulation is to carrying out comparative biochemistry on distinct protein substrates. However, such efforts have been hampered as, with the exception of p53, there is a paucity of MDM2 substrates where direct binding has been demonstrated and coupled with fine mapping studies so that point mutations within the MDM2 interfaces can be made which show a direct link to ubiquitination. We have identified IRF-2 as a novel MDM2 substrate and our characterisation suggests that this protein can be used as a valuable tool to dissect further the complex mechanisms which exist to control MDM2 activity as an E3-ligase [7, 17]. IRF-2 is the only validated protein apart from p53 that has a defined two-site mechanism driving its MDM2-dependent ubiquitination. Thus, the studies reported here, using sequence homology within the p53 ubiquitination signal, to identify novel MDM2 substrates supports the idea that the MDM2 E3-ligase substrate interface is complex encompassing multiple domains on the target substrate $[7,8,18]$.

A role for the acid domain of MDM2 in its activity as an E3-ligase was first suggested by cell based studies where delta acid domain MDM2 mutant constructs were defective in their ability to ubiquitinate p53 [19, 20]. However, a direct role of the acid domain in recognition of p53s ubiquitination signal was not appreciated until recently [7]. Initial studies showed that point mutations within the S9-10 inker region of p53 formed a second docking site for MDM2 on p53 which directly influenced the ability of MDM2 to utilise p53 as an E3ligase substrate [6]. This hypothesis was supported by NMR studies, which demonstrated that the acid domain of MDM2 could interact with a region from within the p53 core [8], and by biochemical analysis, revealing an allosteric regulation of MDM2 which favours binding of the acid domain to the BOXV/S9-10 linker which then is sufficient to signal p53 ubiquitination [7]. Additional support for this model comes from a cell based study showing that constructs containing the acid domain of MDM2 but minus the hydrophobic pocket can still ubiquitinate p53 [21]. In the current study we have used a bioinformatics approach to demonstrate that it is possible to identify proteins capable of binding to MDM2 and acting as an E3-ligase substrate by using the p53 interaction as a template.

Consistent with the acid domain being involved in transient regulatory interactions it has been shown to bind linear interaction motifs in E3-ligase substrates, such as p53 [7] and in the current study IRF-2 (Figure 2). In addition the acid domain binds to inhibitors of MDM2-mediated ubiquitination such as ARF [22] and the Rb1 peptide (Figure 5; [7]). Together with previous data $[7,21]$ the current study therefore suggests that binding of a protein to the hydrophobic pocket of MDM2 is not sufficient for it to act as a substrate, but that substrates like IRF-2 and p53 must also be able to form an interaction with the acid domain (Figure 7). Conversely proteins which interact only with the acid domain, for example ARF, are unlikely to be efficient substrates for MDM2, furthermore as in the case of ARF, are more likely to act as MDM2 
E3-ligase inhibitors [23]. Strong support for the role of the acid domain in dictating MDM2s specific E3-ligase function comes from the use of MDM2/MDM4 chimeric proteins. MDM4, a close relative of MDM2 shares its overall domain structure, having an $\mathrm{N}$-terminal hydrophobic pocket that can bind p53, an acidic region and a C-terminal C2H2C4 RING. However, MDM4 does not appear to have intrinsic activity as a ligase for p53 [20,24] and although MDM4 has a $\mathrm{C} 2 \mathrm{H} 2 \mathrm{C} 4$ RING it is unclear if this supports a ligase function $[25,26]$. Of interest is the fact that although MDM4 has an acidic central region, it bears little sequence homology to the acid domain of MDM2. When chimeric constructs were generated where the acidic domain of MDM4 was substituted for that of MDM2 the protein was not an effective E3-ligase for p53 although it was still capable of auto-ubiquitination and retained the high affinity p53 binding site in its $\mathrm{N}$-terminus $[19,20]$. This supports our observations that peptides which bind to the acid domain inhibit its MDM2 E3ligase activity against specific substrates such as p53 [7] and IRF-2 (Figure 5), whereas hydrophobic binding pockets have no inhibitory activity in the ubiquitination assay. Thus, the acid domain of MDM2 and its specificity for proteins such as p53 and IRF-2 with a conserved acid domain binding motif is key to understanding MDM2s biochemical mechanism.

The available structural information suggests that the isolated acid domain (amino acids 210-304) is disordered in solution and may use a fold-on-binding mechanism to interact with linear interaction motifs in its binding partners [27]. It has been proposed that binding may involve $\beta$-strand addition, presumably through $\beta$-sheet or $\beta$-zipper formation [28]. This fold-on-binding mechanism would presumably enhance the specificity of the acid domain and analysis of the binding consensus would therefore allow us to identify additional substrates for MDM2, as we have done in the case of IRF-2. Data presented in the current study suggests that some MDM2 interactions stabilise or promote recognition of the substrates ubiquitination signal by the acid domain. Our previous studies have demonstrated that the interaction of RNA ligands such as poly-G with MDM2 can generate conformational changes which favour binding of MDM2 to the BOX-V/S9-10 linker region of p53 [6]. Here we have extended these studies to show that poly-G stabilises the interaction between IRF-2 and MDM2. This gain of MDM2 binding affinity is reflected by an increase in E3-ligase activity when poly-G is present at low concentrations (at higher amounts, consistent with previous studies [29], we see poly-G having an inhibitory effect). Poly-G has been reported to interact with both the RING domain and the acid domain of MDM2 [30] thus, exactly how this ligand stabilises or promotes acid domain interacts is unclear and will form the basis for further studies.

Although the physiological significance of an interaction between MDM2 and IRF-2 has not been addressed by the current study we have shown these two proteins can be immunoprecipitated from cells in the same complex (Figure 1). In addition we have preliminary data suggesting that the association between endogenous IRF-2 and MDM2 can be upregulated by dsRNA, a viral mimetic that can stimulate an interferon response. As IRF-2 has been shown to prevent the over production of IFN- $\beta$ by acting as a transcriptional repressor [31] it is possible that MDM2 may play an as yet undefined role in innate immunity. Thus, it will be of interest to determine how MDM2-mediated 
ubiquitination of IRF-2 impacts on its diverse functions in growth control and immunity [32, 33].

In conclusion, the important feature of our current work is the ability to use bioinformatic screens to search for homologous linear interaction motifs derived from p53 with other proteins in the human proteome with the potential to serve as MDM2 protein-docking sites. The use IRF-2 as a substrate for ubiquitination reactions, especially in comparison to tetrameric p53, will provide us with an opportunity to develop deeper insights into the mechanism of E3-mediated substrate ubiquitination. The requirement for two-docking sites in IRF-2 to sensitize the protein to MDM2-mediated ubiquitination indicates, for example, that the dual site docking mechanism that occurs on p53 is not related to the tetrameric structure of the protein. Instead, it is the structure of MDM2 on a generic substrate with two docking sites that predisposes the protein to catalyze E2-mediated ubiquitin transfer. The analysis of other substrates in the human proteome with varying degrees of homology to the two MDM2 docking sites identified in IRF-2 and p53 will also shed further light on the ubiquitin reaction mechanism as well as other physiological mechanisms of MDM2 function in cells.

\section{Methods and Materials}

Antibodies, plasmids and peptides

pcDNA/IRF-2 was constructed from a Hindlil/Xbal fragment containing human IRF-2 ligated into pcDNA3.1. pcDNA/IRF-2MI $\left(\mathrm{Tyr}^{109}\right.$, Leu $^{112}$ and Pro ${ }^{113}$ mutated to Ala) and DNA/IRF-2MV (Tyr ${ }^{272}, \mathrm{Leu}^{274}, \mathrm{Pro}^{275}$ mutanted to Ala), where made using a Quikchange site directed mutagenesis kit (Stratagene). pcDNA-MDM2, pcDNA-MDM2/C464A, pCMV/His-ubiquitin and pT7.7/MDM2 were a gift from Prof. David Lane. pkBluescript/IRF-2 was obtained from Ben Zion Levi and GST-IRF-2 was expressed from a pDEST15 vector coding fulllength human IRF-2 and GFP-IRF-2 was full-length IRF-2 in pDEST53. FK1 and FK2 were supplied by BioMol international; anti-IRF-2 (C-19) polyclonal sera was from Santa Cruz Biotechnology; MAb 4B2 and 2A10 were used to detect MDM2. Biotin labelled peptides were from Mimitopes.

\section{Cell culture, immuno-precipitation and immunoblots}

$\mathrm{H} 1299$ cells were maintained in RPMI (Invitrogen) plus 5\% FCS and 1\% penicillin/streptomycin at $37^{\circ} \mathrm{C}$ and $5 \% \mathrm{CO}_{2}$, whilst $\mathrm{A} 375$ cells grow in DMEM plus $5 \% \mathrm{FCS}$ at $37{ }^{\circ} \mathrm{C}$ and $10 \% \mathrm{CO}_{2}$. The cells were transfected at $80 \%$ confluency using Lipofectamine 2000 (Invitrogen). Immunoblots were carried out as previously described [34]. Immunoprecipitations were performed using published methods [35].

\section{Ubiquitination assays and ELISA}

Cell based ubiquitination assays were carried out as previously described [7]. The in vitro ubiquitination reactions contained $25 \mathrm{mM}$ Hepes $\mathrm{pH} 8.0,10 \mathrm{mM}$ $\mathrm{MgCl}_{2}, 4 \mathrm{mM}$ ATP, $0.5 \mathrm{mM}$ DTT, 0.05\% (v/v) Triton X-100, $0.25 \mathrm{mM}$ benzamidine $10 \mathrm{mM}$ creatine phosphate, 3.5 units $/ \mathrm{ml}$ creatine kinase, ubiquitin or His-tagged ubiquitin $(2 \mu \mathrm{g})$, and E1 (100 nM), E2 (1 $\mu \mathrm{M})$ and GST or His-tagged IRF-2 protein (100 ng). Reactions were started using purified MDM2 (50 ng), incubated for $20 \mathrm{~min}$ at $30{ }^{\circ} \mathrm{C}$ and analysed using $4-12 \%$ 
NuPAGE gels in a MOPS buffer system (Invitrogen) followed by immunoblot. For the peptide ELISA biotin-labelled peptides were captured onto streptavidin coated plates as detailed in the figure legends. Non-reactive sites were blocked using PBS containing 3\%BSA and the wells were incubated with empirically determined amounts of MDM2 protein (in the presence or absence of added ligand) in PBS- $0.1 \%$ BSA for $1 \mathrm{~h}$ at RT. The plates were washed extensively with PBS-0.1\% Tween and MDM2 binding was detected using 2A10 and enhanced chemiluminescence. The protein ELISA's were performed by coating white 96 well plates with the protein of interest (as detailed in the figure legends) in $0.1 \mathrm{M}$ sodium borate. Non-reactive sites were blocked using PBS containing 3\%BSA and the wells were incubated with empirically determined amounts of MDM2 or IRF-2 protein in PBS-0.1\%BSA for $1 \mathrm{~h}$ at RT. Binding was detected using the appropriate primary antibodies following previously published methods [7].

\section{Protein preparation}

MDM2 was expressed and purified as previously described [36]. GST-IRF-2 and His-IRF-2 were purified on glutathione-Sepharose and nickle-agarose, respectively, following the manufactures instructions. Untagged-IRF-2 was expressed from pkBluescript/IRF-2 transformed E.coli BL21 following treatment with $0.5 \mathrm{mM}$ IPTG for $2 \mathrm{~h}$ at RT. Following harvesting the bacteria were resuspended in an equal volume of $50 \mathrm{mM}$ Hepes, $\mathrm{pH} 8.0$ containing $10 \%$ sucrose and frozen in liquid nitrogen. The cells were thawed in an icewater bath in the presence of $0.25 \mathrm{M} \mathrm{KCl}, 2 \mathrm{mM} \mathrm{DTT}, 0.5 \mathrm{mg} / \mathrm{ml}$ lysozyme, and $400 \mu \mathrm{g} / \mathrm{ml}$ Pefabloc (final concentrations) and incubated at $4^{\circ} \mathrm{C}$ for $30 \mathrm{~min}$ prior to centrifugation at $10000 \times \mathrm{g}$ for $15 \mathrm{~min}$. The supernatant was removed and diluted to $10 \mathrm{mg} / \mathrm{ml}$ total protein using column buffer $(50 \mathrm{mM}$ Hepes, $\mathrm{pH}$ 7.6 containing 10\% glycerol, $0.1 \mathrm{mM}$ EDTA, 2 mM DTT, $0.1 \%$ Triton X-100, $400 \mu \mathrm{g} / \mathrm{ml}$ Pefabloc, $1 \mathrm{mM}$ benzamidine) and applied to a heparin-Poros column equilibrated in column buffer plus $100 \mathrm{mM} \mathrm{NaCl}$. The column was washed with column buffer plus $100 \mathrm{mM} \mathrm{NaCl}$ and eluted with a linear gradient of $0.1-1.0 \mathrm{M} \mathrm{NaCl}$. Fractions containing IRF-2 protein, as determined using immunoblots, were pooled concentrated to $>1 \mathrm{mg} / \mathrm{ml}$, aliquoted and frozen in liquid nitrogen.

\section{Figure Legends}

Figure 1: Identification of IRF-2 as a novel MDM2 binding protein.

(A) Alignment of MDM2 binding regions from p53 (the BOX-I and BOX-V domains) with homolgous regions from IRF-2. (B) A375 cells were transfected with $2 \mu \mathrm{g}$ each of IRF-2 and MDM2. IRF-2 was immunoprecipitated from the lysate using C-19; immunoblots were developed using C-19 or the anti-MDM2 $\lg$ G 2 A10. The controls are lysate $(1 / 10$ that added to the IP) and recombinant IRF-2 (IRF-2). The results are representative of 2 separate experiments. (C) $\mathrm{H} 1299$ cells were transfected with $0.1 \mu \mathrm{g}$ each of GFP-IRF2 and MDM2. MDM2 was detected using 4B2 (1:1000 dilution) and an Alexa-conjugated goat anti-mouse secondary; the nuclei were counterstained with DAPI. (D) A titration of MDM2 (top panel: 0 - $0.5 \mu \mathrm{g} /$ well) or IRF-2 protein (bottom panel: $0-0.75 \mu \mathrm{g} /$ well) was captured on a micro-titre plate and incubated with either IRF-2 or MDM2 respectively ( 0.1 or $0.5 \mu \mathrm{g} /$ well). Bound IRF-2 or MDM2 was 
detected using C19 or 2A10, respectively. The data is expressed as Relative Light Units (RLU) and is representative of 2 individual experiments.

Figure 2: MDM2-dependent ubiquitination of IRF-2 in vitro and in cells. (A) H1299 cells were transfected with $2 \mu \mathrm{g}$ each of His-ubiquitin (His-Ub), IRF-2, MDM2 or MDM2/C464A. Ubiquitinated protein was isolated $24 \mathrm{~h}$ post transfection and analysed by SDS-PAGE/immunoblot (upper panel). Total IRF-2 was detected by immunoblot following non-denaturing cell lysis (lower panel). IRF-2 was detected using $\mathrm{C} 19$ and $\mathrm{C}$ is recombinant IRF-2. This data is representative of at least 5 separate experiments. (B) GST-IRF-2 $(0.1 \mu \mathrm{g})$ was incubated with E1 $(100 \mathrm{nM})$ and $\mathrm{E} 2(1 \mu \mathrm{M})$ in the presence or absence of ubiquitin $(2 \mu \mathrm{M})$ and MDM2 (50 ng) for 15, 30 and 45 min. Ubiquitination of IRF-2 was analyzed by immunoblot, developed using C19. (C) GST-IRF-2 $(0.1 \mu \mathrm{g})$ was incubated for 20 min with $\mathrm{E} 1(100 \mathrm{nM}), \mathrm{E} 2(1 \mu \mathrm{M})$, ubiquitin (2 $\mu \mathrm{M})$ and increasing amounts of MDM2 (5-50 $\mu \mathrm{g})$. Ubiquitination was detected by immunoblot developed with $\mathrm{C} 19$.

Figure 3: MDM2 mediated monoubiquitination of IRF-2

(A) GST-IRF-2 $(0.1 \mu \mathrm{g})$ was incubated with E1 (100 nM), E2 $(1 \mu \mathrm{M})$ and ubiquitin $(2 \mu \mathrm{M})$ in the presence or absence of MDM2. IRF-2 was detected with C19, poly- and mono-ubiquitination were detected using FK2, and polyubiquitination by FK1. The results are representative of 2 separate experiments. (B) GST-IRF-2 (100 ng) was incubated with E1 (100 nM), E2 (1 $\mu \mathrm{M})$ in the presence or absence of MDM2 (50 ng) with ubiquitin $(2 \mu \mathrm{M})$ or K48R ubiquitin $(2 \mu \mathrm{M})$. Ubiquitinated IRF-2 was detected by immunoblot as above. The results are representative of 4 independent experiments.

Figure 4: Structural requirements for MDM2 mediated ubiquitination of IRF-2. (A) His-IRF-2 $(0.1 \mu \mathrm{g})$ was incubated with E1 (100 nM), E2 $(1 \mu \mathrm{M})$ and ubiquitin $(2 \mu \mathrm{M})$ in presence of equal amounts of GST-MDM2wt, GSTMDM2 $\triangle$ N or GST-MDM2 $A$ Ac. IRF-2 was detected by immunoblot using C19 antisera and MDM2 was detected using 2A10. The results are representative of 2 experiments. (B) Schematic of the mutants used in part C, where the underlined residues have been mutated to Ala. (C) GST-IRF-2, -IRF-2MI and IRF-2MV were incubated with E1 (100 nM), E2 (1 $\mu \mathrm{M})$, and ubiquitin $(2 \mu \mathrm{M})$ with increasing amounts of MDM2 (5-50 ng). Ubiquitination of wild type and mutant IRF-2 was analyzed by immunoblot as above. The results are representative of at least 3 individual experiemnts.

Figure 5: MDM2 acid domain interacting ligands inhibit MDM2-mediated ubiquitination of IRF-2.

(A) Schematic of full length MDM2 showing its binding domain ligand specificity. Nutlin and BOX-I peptide bind to the hydrophobic pocket whereas $\mathrm{Rb} 1$ and $\mathrm{BOX}-\mathrm{V}$ interact with the acid domain. (B) IRF-2 $(0.1 \mu \mathrm{g})$ was incubated with E1 (100 nM), E2 (1 $\mu \mathrm{M})$, ubiquitin $(2 \mu \mathrm{M})$ and MDM2 (50 ng) for 20 min Nutlin, BOX-I or Rb1 peptides were added as indicated. Ubiquitination of IRF-2 was analyzed by immunoblot, developed using C19. (C) GST-IRF2 $(0.1 \mu \mathrm{g})$ was incubated with E1 $(100 \mathrm{nM})$ and E2 $(1 \mu \mathrm{M})$; ubiquitin $(2 \mu \mathrm{M})$ and MDM2 (50 ng) were present as indicated. A titration (12, 25 and $50 \mu \mathrm{M}$ ) of Rb1 (lanes 4-6), BOX-I (lane 7-9) or BOX-V peptide (lane 
10-12) was added to the assay as indicated. The results are representative of 2 separate experiments.

Figure 6: Ligand stimulated increases in MDM2 activity are mediated by the acid domain.

(A) IRF-2 (500 ng/well) or MDM2 (200 ng) was captured onto a micro-titre plate and incubated with MDM2 or IRF-2 (200 ng and 500 ng, respectively) that had been pre-incubated with a titration of poly-G $(0.25-1.0 \mu \mathrm{g} / \mathrm{well})$. Bound IRF-2 or MDM2 was detected using C-19 or 2A10, respectively. The data in the left hand panel is expressed as Relative Light Units (RLU) and is representative of at least 2 independent experiments. The data in the right hand panel is for MDM2 binding to immobilised IRF-2 and shows RLU as a \% maximal MDM2 binding. The mean \pm standard error, where $n=4$ is shown.

(B) His-IRF-2 (100 ng) was incubated with E1 (100 nM), E2 (1 $\mu \mathrm{M})$, ubiquitin $(2 \mu \mathrm{M})$ and MDM2 (50 ng) in the absence or presence of a poly- $\mathrm{G}$ titration $(0.05,0.1,0.2$ or $4 \mu \mathrm{g})$. IRF-2 was detected by immunoblot using $\mathrm{C} 19$ antisera. (C) His-IRF-2 was incubated with E1 (100 nM), E2 (1 $\mu \mathrm{M})$, ubiquitin $(2 \mu \mathrm{M})$ and MDM2 (50 ng) in the absence or presence of a poly- $\mathrm{G}$ titration $(0.05,0.1,0.2$ or $4 \mu \mathrm{g}$; lane $1-5)$ or with $0.1 \mu \mathrm{g}$ poly-G in the absence or presence of $\mathrm{Rb} 1(12,25$ or $50 \mu \mathrm{M}$; lane 6-9). IRF-2 was detected by immunoblot as above and the results are respresntative of 2 separate experiments.

Figure 7: A model for MDM2 mode of action.

Evidence presented here and previously [7] suggests that MDM2 substrates need to interact with both the hydrophobic pocket $(\mathrm{Hy})$ and the acid domain (Ac) in order to be ubiquitinated (I.). Ligands which bind to the acid domain, but not the pocket, can inhibit ubiquitination, suggesting that the acid domain is primarily involved in recognition of the substrates ubiquitination signal. We show that ligands such as RNA (II.) which have been reported to interact with the acid and/or RING domain (R) $[27,28]$ activate MDM2 mediated ubiquitination, by favouring binding to the substrates ubiquitination signal [6]. Thus, RNA may stabilise the acid domain in a more favourable binding conformation.

\section{Acknowledgements}

KLB is a CRUK programme grant holder MK was funded by a studentship from CRUK. We would like to thank Ted Hupp for his valuable input and support.

\section{References}

1 Vousden, K. H. and Lane, D. P. (2007) p53 in health and disease. Nat. Rev. Mol. Cell. Biol. 8, 275-283

2 Hupp, T. R. and Walkinshaw, M. (2007) Multienzyme assembly of a p53 transcription complex. Nat. Struct. Mol. Biol. 14, 885-887

3 Bond, G. L., Hu, W. and Levine, A. J. (2005) MDM2 is a central node in the p53 pathway: 12 years and counting. Curr. Cancer Drug Targets 5, 3-8 
Zhang, Z. and Zhang, R. (2005) p53-independent activities of MDM2 and their relevance to cancer therapy. Curr. Cancer Drug Targets 5, 920

5 Kussie, P. H., Gorina, S., Marechal, V., Elenbaas, B., Moreau, J., Levine, A. J. and Pavletich, N. P. (1996) Structure of the MDM2 oncoprotein bound to the p53 tumor suppressor transactivation domain. Science 274, 948-953.

6 Shimizu, H., Burch, L. R., Smith, A. J., Dornan, D., Wallace, M., Ball, K. L. and Hupp, T. R. (2002) The conformationally flexible S9-S10 linker region in the core domain of p53 contains a novel MDM2 binding site whose mutation increases ubiquitination of p53 in vivo. J. Biol. Chem. 277, 28446-28458

7 Wallace, M., Worrall, E., Pettersson, S., Hupp, T. R. and Ball, K. L. (2006) Dual-Site Regulation of MDM2 E3-Ubiquitin Ligase Activity. Mol. Cell 23, 251-263

8 Yu, G. W., Rudiger, S., Veprintsev, D., Freund, S., FernandezFernandez, M. R. and Fersht, A. R. (2006) The central region of HDM2 provides a second binding site for p53. Proc. Natl. Acad. Sci. U S A 103, 1227-1232

9 Terzian, T., Suh, Y. A., Iwakuma, T., Post, S. M., Neumann, M., Lang, G. A., Van Pelt, C. S. and Lozano, G. (2008) The inherent instability of mutant p53 is alleviated by Mdm2 or p16INK4a loss. Genes Dev. 22, 1337-1344

10 Taniguchi, T., Ogasawara, K., Takaoka, A. and Tanaka, N. (2001) IRF family of transcription factors as regulators of host defense. Annu Rev Immunol 19, 623-655

11 Treier, M., Staszewski, L. M. and Bohmann, D. (1994) Ubiquitindependent c-Jun degradation in vivo is mediated by the delta domain. Cell 78, 787-798

12 Honda, R., Tanaka, H. and Yasuda, H. (1997) Oncoprotein MDM2 is a ubiquitin ligase E3 for tumor suppressor p53. FEBS Lett. 420, 25-27.

13 Poyurovsky, M. V., Priest, C., Kentsis, A., Borden, K. L., Pan, Z. Q., Pavletich, N. and Prives, C. (2007) The Mdm2 RING domain Cterminus is required for supramolecular assembly and ubiquitin ligase activity. Embo J. 26, 90-101

14 Vassilev, L. T., Vu, B. T., Graves, B., Carvajal, D., Podlaski, F., Filipovic, Z., Kong, N., Kammlott, U., Lukacs, C., Klein, C., Fotouhi, N. and Liu, E. A. (2004) In vivo activation of the p53 pathway by smallmolecule antagonists of MDM2. Science 303, 844-848

15 Dornan, D and Hupp, T. R. (2001) Inhibition of p53-dependent transcription by BOX-I phospho-peptide mimetics that bind to $\mathrm{p} 300$. EMBO Rep. 2, 139-144.

16 Buolamwini, J. K., Addo, J., Kamath, S., Patil, S., Mason, D. and Ores, M. (2005) Small molecule antagonists of the MDM2 oncoprotein as anticancer agents. Curr. Cancer Drug Targets 5, 57-68

17 Shimizu, H. and Hupp, T. R. (2003) Intrasteric regulation of MDM2. Trends Biochem. Sci. 28, 346-349

18 Schon, O., Friedler, A., Bycroft, M., Freund, S. M. and Fersht, A. R. (2002) Molecular mechanism of the interaction between MDM2 and p53. J. Mol. Biol. 323, 491-501 
19 Meulmeester, E., Frenk, R., Stad, R., de Graaf, P., Marine, J. C., Vousden, K. H. and Jochemsen, A. G. (2003) Critical role for a central part of Mdm2 in the ubiquitylation of p53. Mol. Cell. Biol. 23, 4929-4938

20 Kawai, H., Wiederschain, D. and Yuan, Z. M. (2003) Critical contribution of the MDM2 acidic domain to p53 ubiquitination. Mol. Cell. Biol. 23, 4939-4947

21 Kulikov, R., Winter, M. and Blattner, C. (2006) Binding of p53 to the central domain of Mdm2 is regulated by phosphorylation. J. Biol. Chem. 281, 28575-28583

22 Midgley, C. A., Desterro, J. M., Saville, M. K., Howard, S., Sparks, A., Hay, R. T. and Lane, D. P. (2000) An N-terminal p14ARF peptide blocks Mdm2-dependent ubiquitination in vitro and can activate p53 in vivo. Oncogene 19, 2312-2323

23 Zhang, Y. and Xiong, Y. (2001) Control of p53 ubiquitination and nuclear export by MDM2 and ARF. Cell Growth Differ. 12, 175-186

24 Stad, R., Little, N. A., Xirodimas, D. P., Frenk, R., van der Eb, A. J., Lane, D. P., Saville, M. K. and Jochemsen, A. G. (2001) Mdmx stabilizes p53 and Mdm2 via two distinct mechanisms. EMBO Rep. 2, 1029-1034

25 Badciong, J. C. and Haas, A. L. (2002) MdmX is a RING finger ubiquitin ligase capable of synergistically enhancing Mdm2 ubiquitination. J. Biol. Chem. 277, 49668-49675

26 Linares, L. K., Hengstermann, A., Ciechanover, A., Muller, S. and Scheffner, M. (2003) HdmX stimulates Hdm2-mediated ubiquitination and degradation of p53. Proc. Nati. Acad. Sci. U S A 100, 12009-12014

27 Bothner, B., Lewis, W. S., DiGiammarino, E. L., Weber, J. D., Bothner, S. J. and Kriwacki, R. W. (2001) Defining the molecular basis of Arf and $\mathrm{Hdm} 2$ interactions. J. Mol. Biol. 314, 263-277

28 Remaut, H. and Waksman, G. (2006) Protein-protein interaction through beta-strand addition. Trends Biochem. Sci. 31, 436-444

29 Linares, L. K. and Scheffner, M. (2003) The ubiquitin-protein ligase activity of Hdm2 is inhibited by nucleic acids. FEBS Lett. 554, 73-76

30 Elenbaas, B., Dobbelstein, M., Roth, J., Shenk, T. and Levine, A. J. (1996) The MDM2 oncoprotein binds specifically to RNA through its RING finger domain. Mol. Med. 2, 439-451

31 Senger, K., Merika, M., Agalioti, T., Yie, J., Escalante, C. R., Chen, G., Aggarwal, A. K. and Thanos, D. (2000) Gene repression by coactivator repulsion. Mol Cell. 6, 931-937

32 Stellacci, E., Testa, U., Petrucci, E., Benedetti, E., Orsatti, R., Feccia, T., Stafsnes, M., Coccia, E. M., Marziali, G. and Battistini, A. (2004) Interferon regulatory factor-2 drives megakaryocytic differentiation. Biochem. J. 377, 367-378

33 Passioura, T., Shen, S., Symonds, G. and Dolnikov, A. (2005) A retroviral library genetic screen identifies IRF-2 as an inhibitor of N-rasinduced growth suppression in leukemic cells. Oncogene 24, 73277336

34 Pamment, J., Ramsay, E., Kelleher, M., Dornan, D. and Ball, K. L. (2002) Regulation of the IRF-1 tumour modifier during the response to genotoxic stress involves an ATM-dependent signalling pathway. Oncogene 21, 7776-7785 
35 Gannon, J. V., Greaves, R., Iggo, R. and Lane, D. P. (1990) Activating mutations in p53 produce a common conformational effect. A monoclonal antibody specific for the mutant form. Embo J. 9, 15951602

36 Wawrzynow, B., Zylicz, A., Wallace, M., Hupp, T. and Zylicz, M. (2007) MDM2 chaperones the p53 tumor suppressor. J. Biol. Chem. 282, 32603-32612 
Figure 1

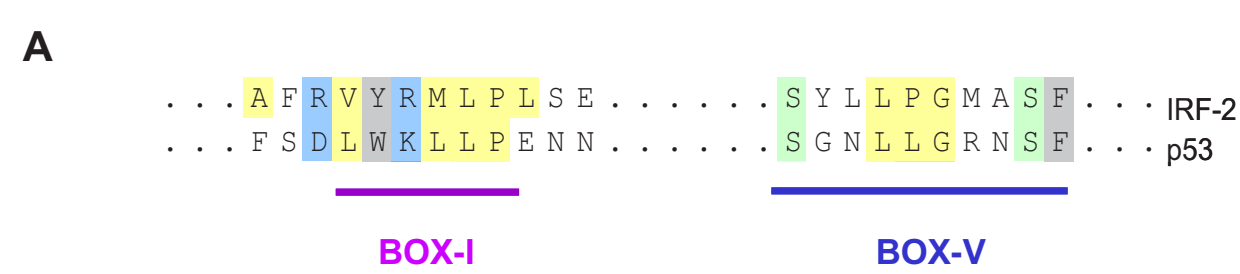

Key:

Aromatic Hydrophilic Hydrophobic Charged

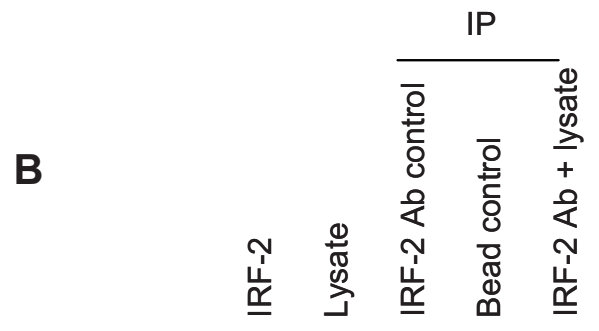

C
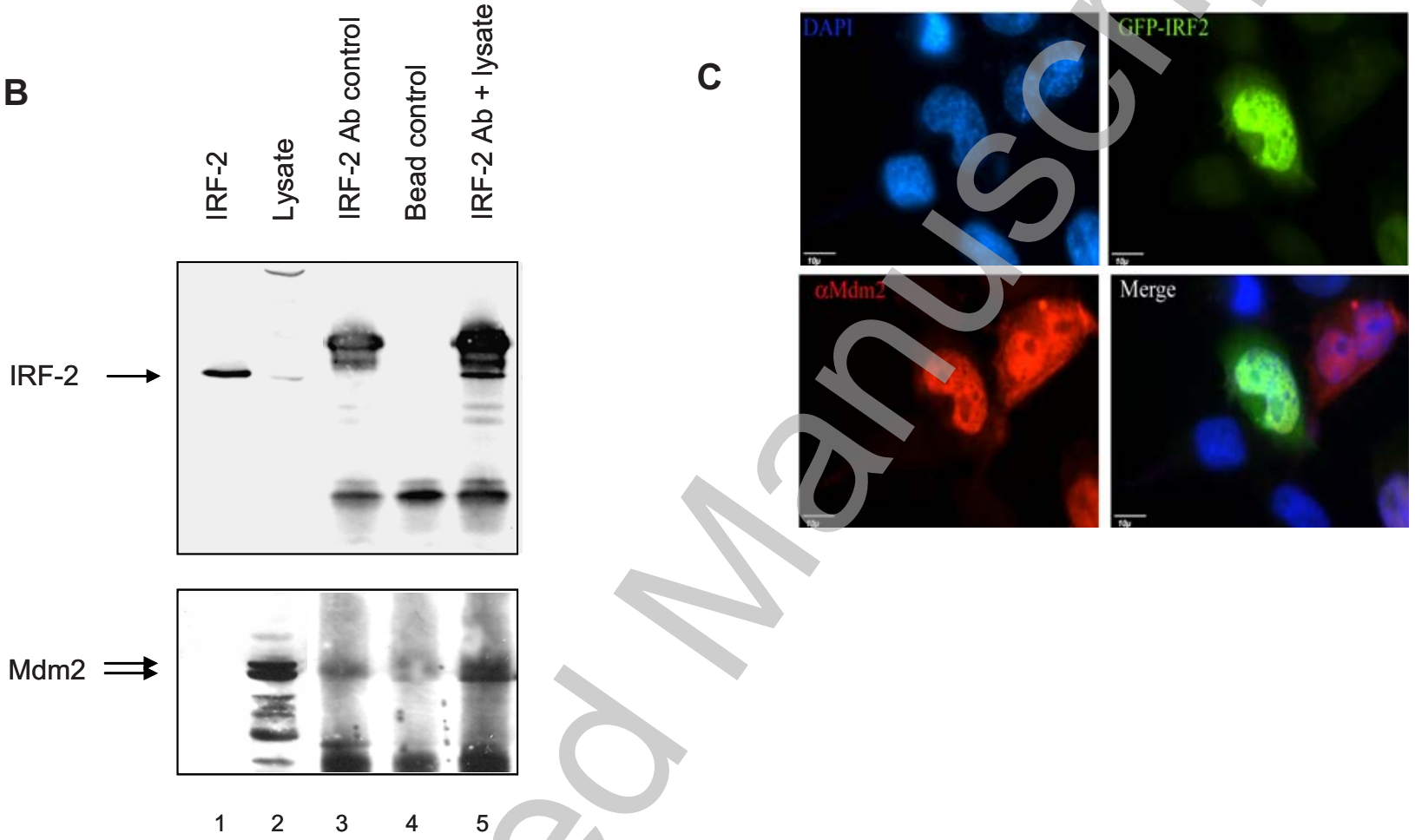

D
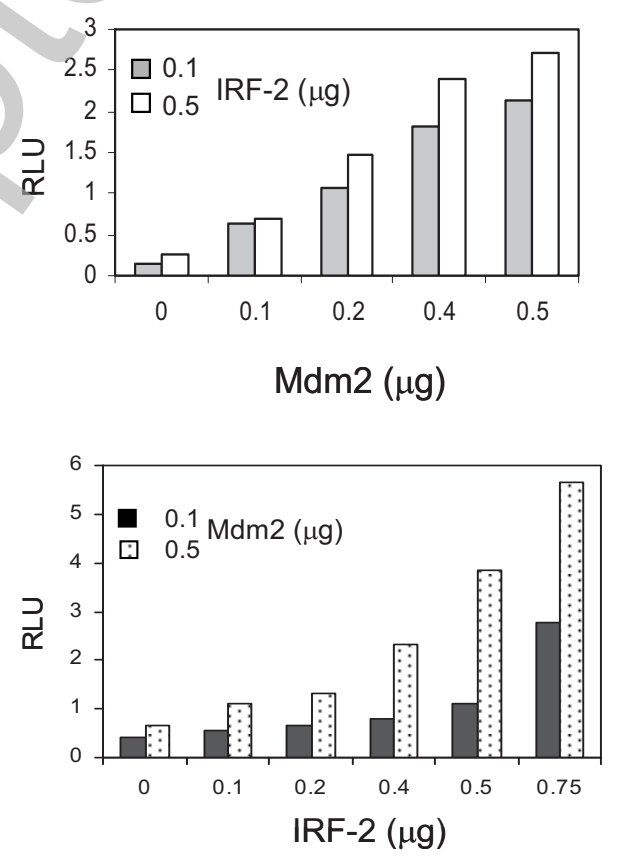

Licenced copy. Copying is not permitted, except with prior permission and as allowed by law. (c) 2008 The Authors Journal compilation (c) 2008 Biochemical Society 
Figure 2

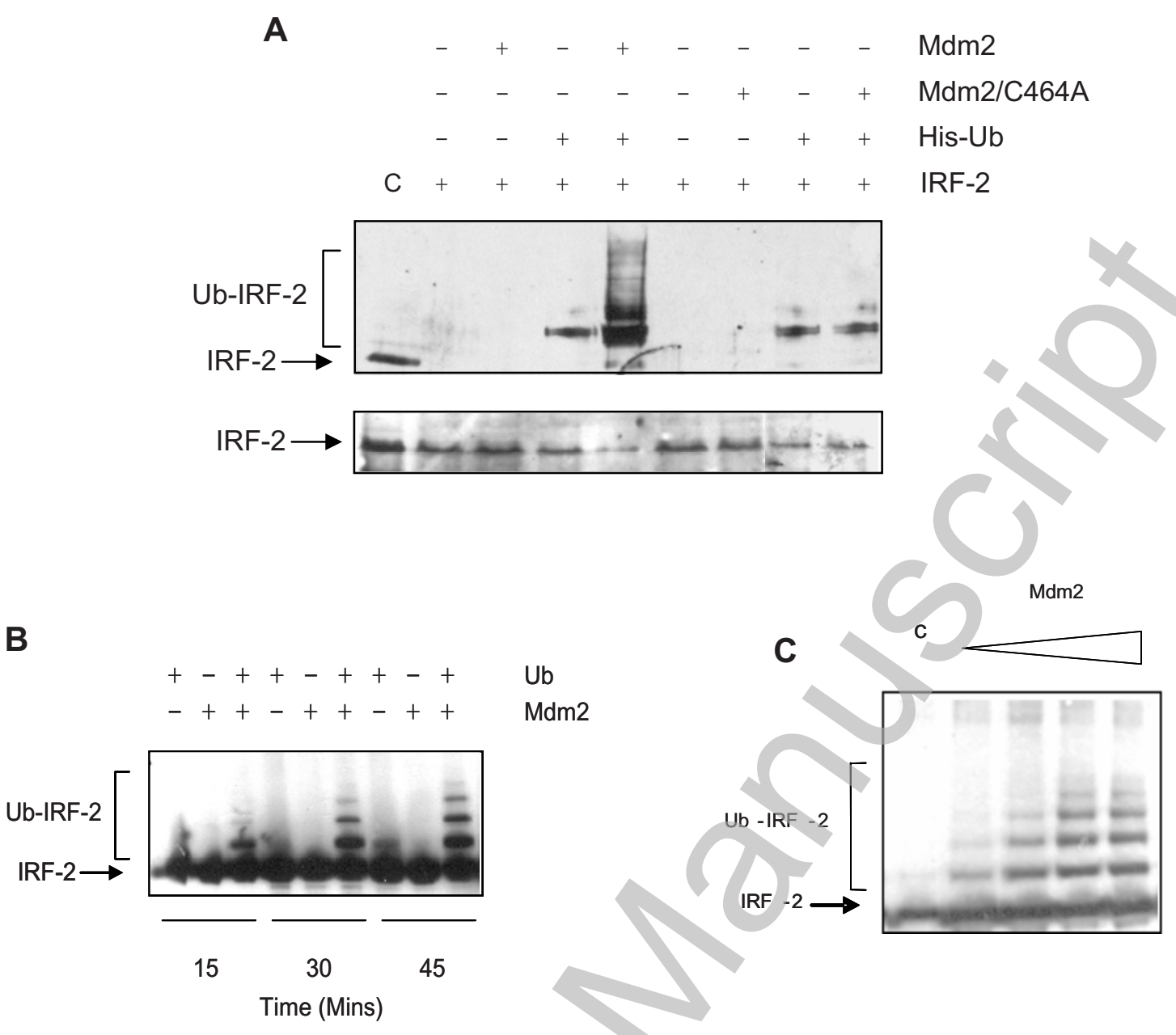

B 
Figure 3
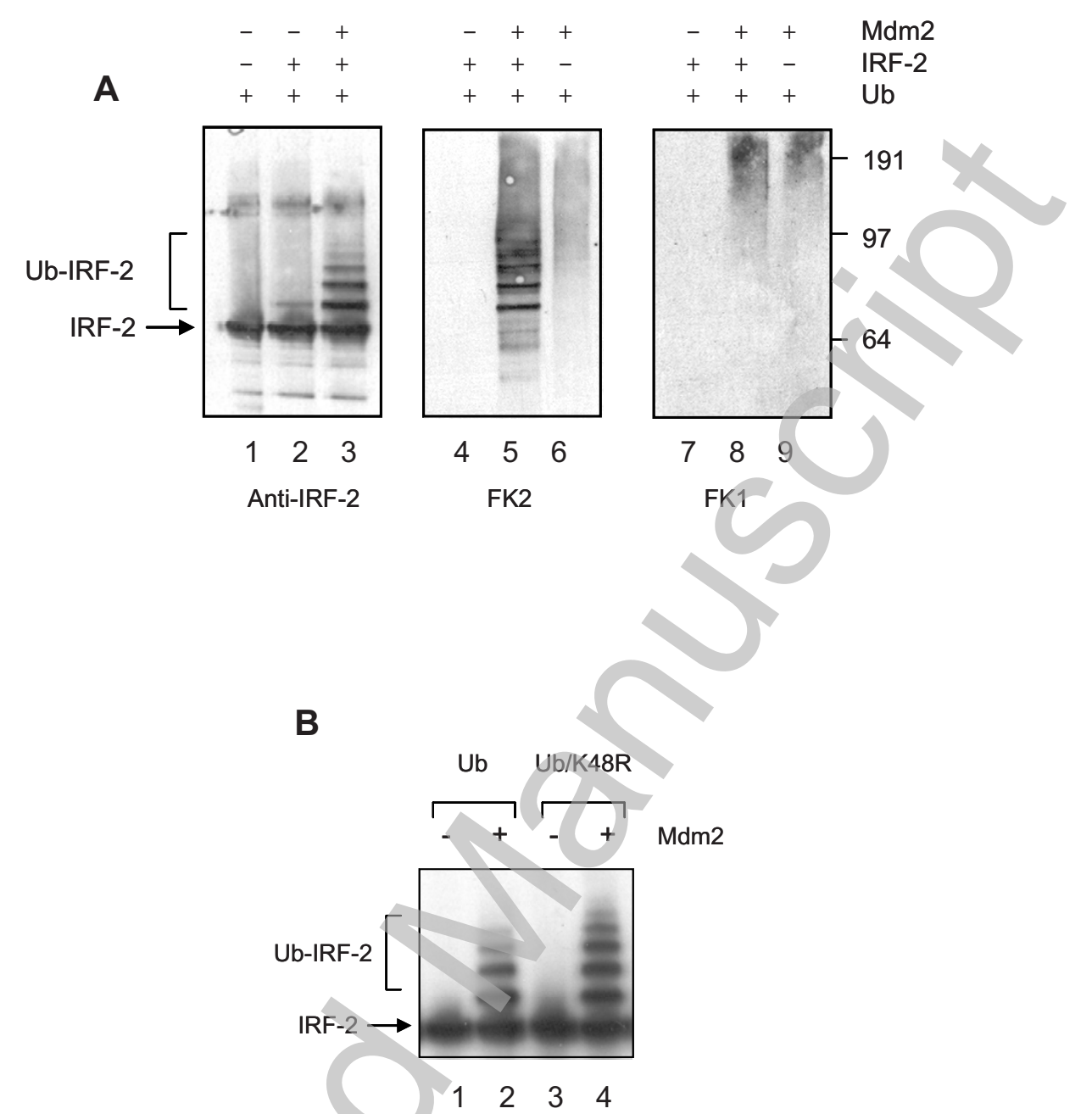
Figure 4

A
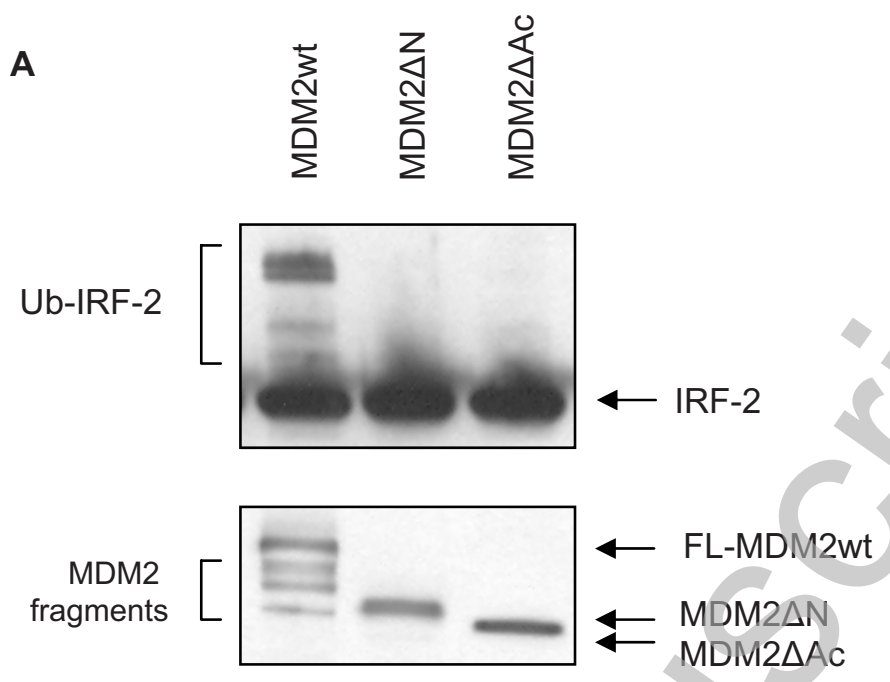

B

IRF-2MI

IRF-2MV
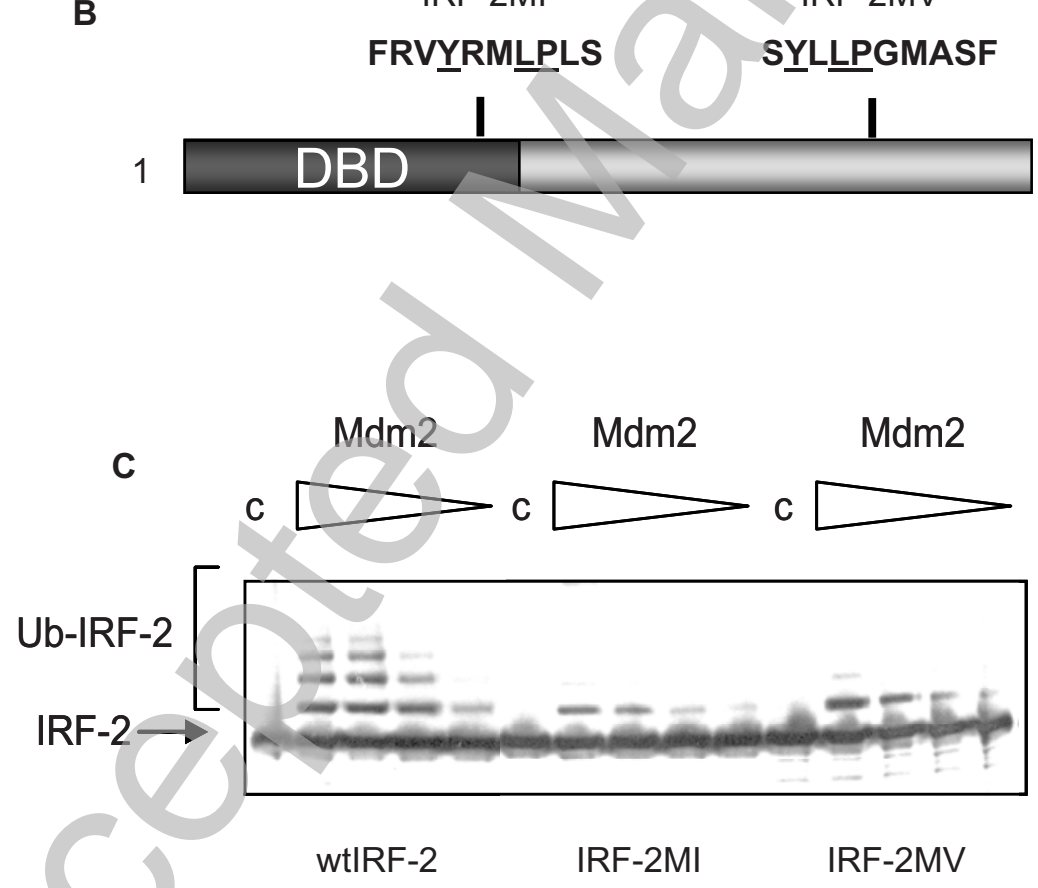
Biochemical Journal Immediate Publication. Published on 25 Nov 2008 as manuscript BJ20082087

Figure 5

A
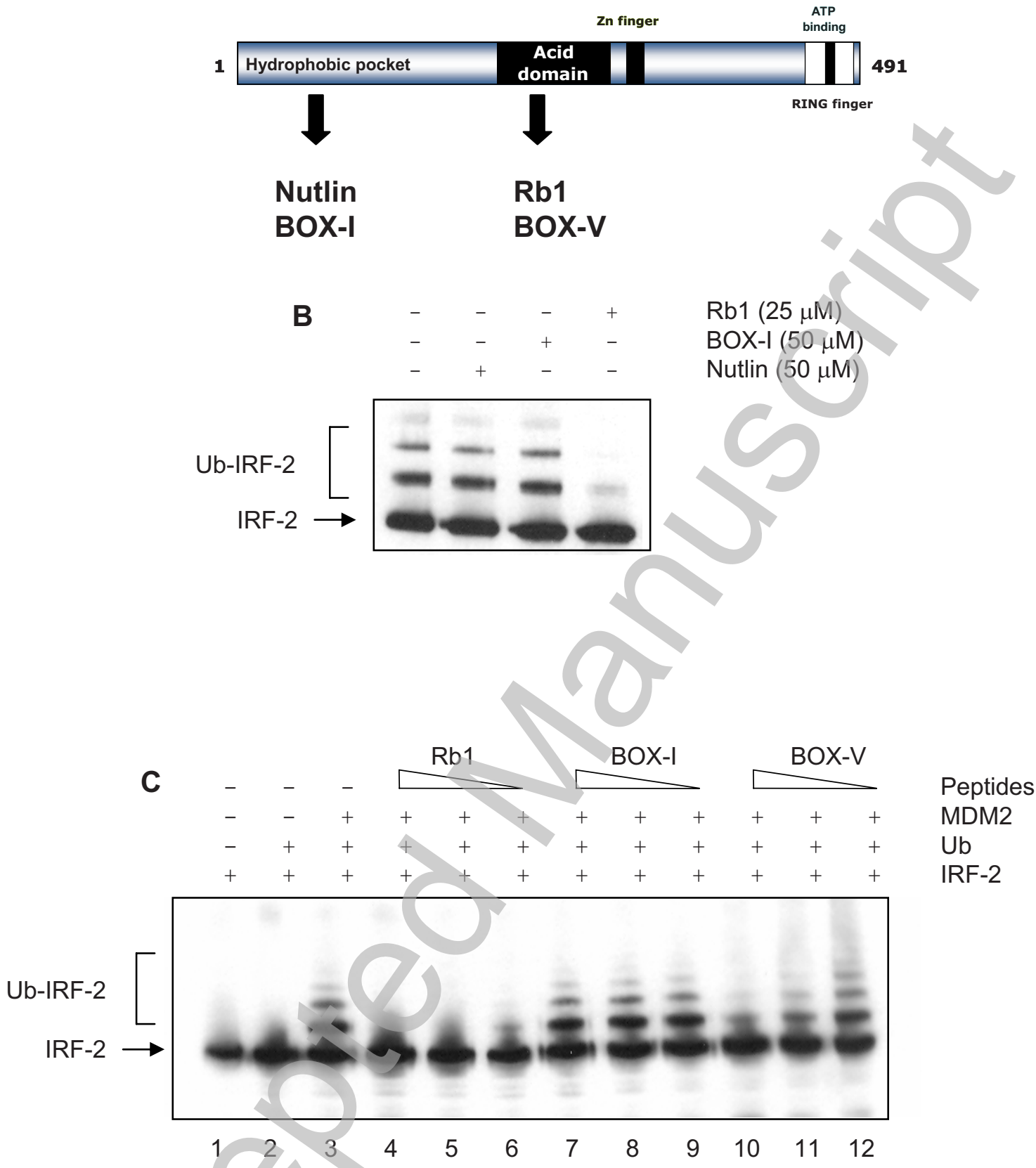
Figure 6

\section{A}

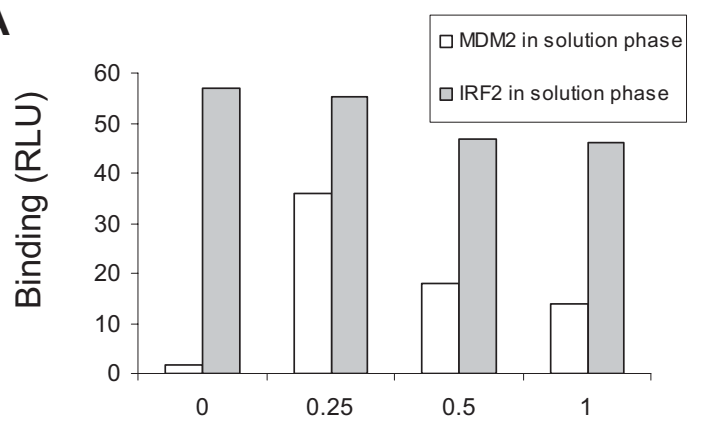

Poly-G $(\mu \mathrm{g})$

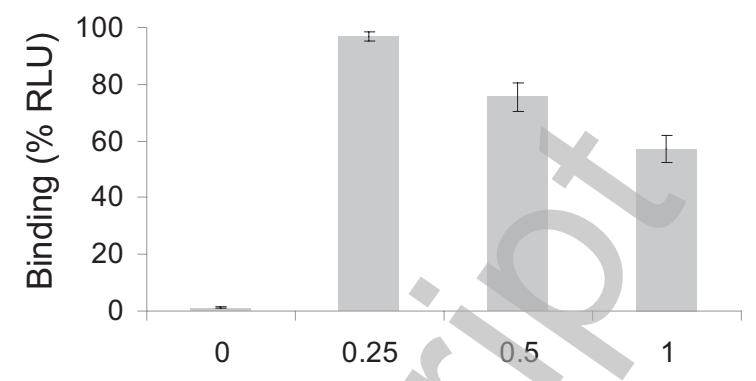

Poly-G ( $\mu g)$

B

Poly-G

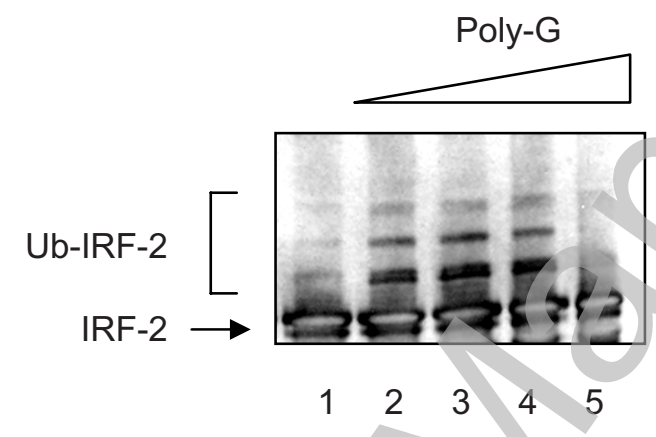

C

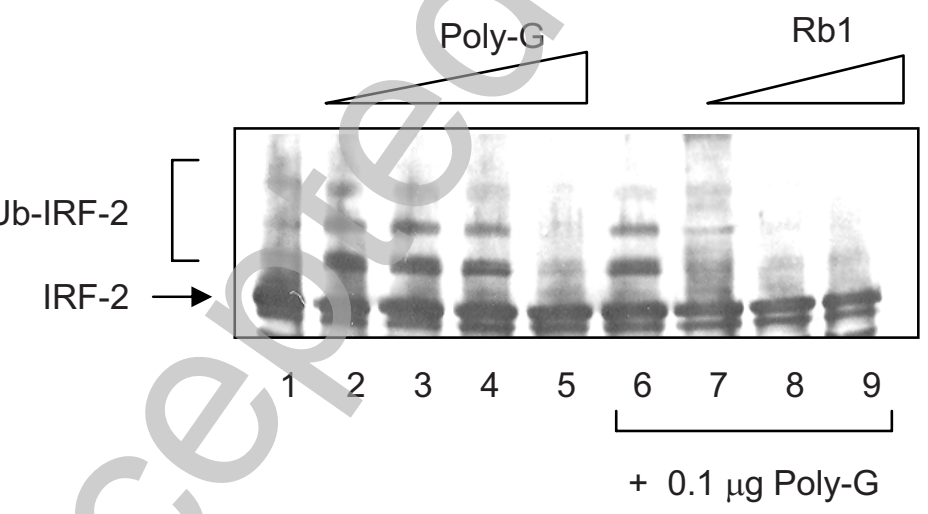

Licenced copy. Copying is not permitted, except with prior permission and as allowed by law. (c) 2008 The Authors Journal compilation (c) 2008 Biochemical Society 
Figure 7

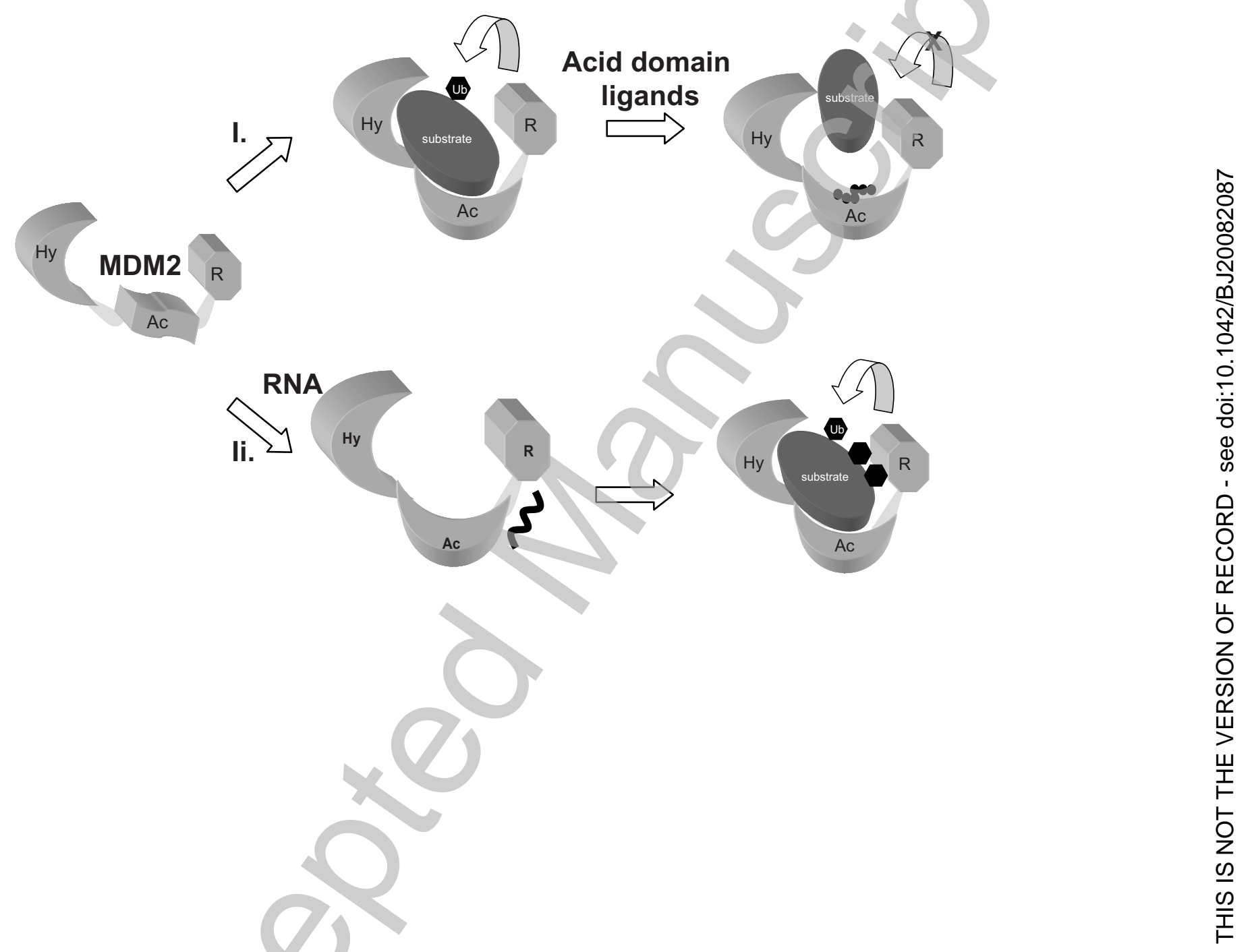

